\title{
Eight polymorphic microsatellite markers for the spotted babylon, Babylonia areolata (Buccinidae)
}

\author{
Y. Wang, H. Lu, J. Zheng, K. Long, Y.H. Shi, Z.F. Gu and A.M. Wang
}

Key Laboratory of Tropical Biological Resources, Ministry of Education, Hainan Provincial Key Laboratory of Tropical Hydrobiology and Biotechnology, Marine Biology Experiment Teaching Demonstration Center, Ocean College, Hainan University, Haikou, Hainan, China

Corresponding authors: A.M. Wang / Y. Wang

E-mail: aimwang@163.com / wy2005@163.com

Genet. Mol. Res. 10 (4): 3230-3235 (2011)

Received June 28, 2011

Accepted August 19, 2011

Published December 21, 2011

DOI http://dx.doi.org/10.4238/2011.December.21.5

\begin{abstract}
The spotted babylon, Babylonia areolata, is one of the most extensively cultured marine mollusks in southeast Asia. Eight polymorphic microsatellite markers were developed for this species, from a microsatellite-enriched library. These markers, characterized in 32 individuals from a hatchery population, were polymorphic, with allele numbers ranging from 6 to 18 per locus, expected and observed heterozygosities ranging from 0.68 to 0.94 and 0.56 to 0.81 , respectively. One locus (HUBA09) showed significant deviation from Hardy-Weinberg equilibrium, probably due to the presence of null alleles. These microsatellite loci should be useful for future population genetic studies and marker-assisted breeding in this species.
\end{abstract}

Key words: Babylonia areolata; Microsatellites; Population genetics; Aquaculture; Spotted babylon 


\section{INTRODUCTION}

The spotted babylon Babylonia areolata (Link, 1807), also called the maculated ivory whelk, is a marine gastropod mollusc distributed in southeastern Asia. Its geographic distribution stretches from Ceylon and Nicobar Islands through the Gulf of Thailand, along Vietnamese and Chinese coasts to Taiwan (Altena and Gittenberger, 1981). It is mostly found on muddy and sandy littoral bottoms not exceeding 5-10 $\mathrm{m}$ in depth (Panichasuk, 1996). The spotted babylon is a popular model mollusc used in studies on heavy-metal toxicity and on the transmission of biological toxins (Chen and Chou, 1998; Supanopas et al., 2005), since it is a popular and nutritious seafood. In recent years, wild populations have rapidly declined due to fast-growing demand for consumption and to environmental pollution. The spotted babylon has been a commercially important aquaculture species in Thailand (Chaitanawisuti et al., 2002; Kritsanapuntu et al., 2006) and China (Liang et al., 2005). The individuals from Thailand have greater growth vigor than native ones in Hainan Island, so most hatchery populations in Hainan come from Thailand lines. However, little is known about the genetic structure and variation of this species, especially in hatchery lines (Hualkasin et al., 2008; Chen et al., 2011). Microsatellite markers are a powerful tool in population structure analyses, genetic linkage map construction (Reece et al., 2004), parentage assignment, and marker-assisted breeding (Wang et al., 2010b), owing to their codominant and highly polymorphic nature, as well as the reliability and testability in PCR and genotyping. To support population structure analyses and facilitate stock management, we developed a microsatellite-enriched library and characterized 8 polymorphic microsatellite markers for the spotted babylon.

\section{MATERIAL AND METHODS}

\section{Samples and DNA extraction}

Thirty-two B. areolata individuals were sampled from a hatchery population at Hainan Dingda Aquaculture Co. Ltd. (Wenchang, Hainan, China) in 2010 (coded Dd10). The population was the $\mathrm{F}_{1}$ progeny of Thailand wild-caught broodstock that had been imported. DNA was extracted from the ethanol-preserved gastropod muscles using the Cell/Tissue Genomic DNA extraction kit (TianGen, Beijing, China).

\section{Microsatellite-enriched library construction and sequencing}

A microsatellite-enriched DNA library was constructed using a modified magnetic bead enrichment protocol as described by Wang et al. (2010a). Briefly, about $38 \mu \mathrm{g}$ genomic DNA from three individuals was digested by the restriction enzyme MboI (Takara, Dalian, China). Fragments of 300-1000 bp, collected with the Gel DNA Extraction kit (TianGen), were ligated to double-strand $\mathrm{MboI}$ adapters by incubating with T4 DNA ligase (Takara) at $16^{\circ} \mathrm{C}$ overnight. Excess adapters were removed by washing with $0.1 \mathrm{X}$ TE buffer, $\mathrm{pH}$ 8.0, on an Ultrafree column (Pall, CA, USA). DNA fragments with adapters were amplified with linker B (one strand of $\mathrm{MboI}$ adapter) for 5 PCR cycles and purified using an Ultrafree column (Pall). The amplified products were denatured and then hybridized to biotin-labeled (CA) ${ }_{12},(\mathrm{GA})_{12}$, $(\mathrm{ACA})_{8},(\mathrm{AGA})_{8},(\mathrm{GACA})_{6}$, and (GATA) ${ }_{6}$ oligonucleotides (mixed in advance at a ratio of 
3:1:1:1:2:2, total $150 \mathrm{pmol}$ ) in $0.5 \mathrm{X} \mathrm{SSC}$ at $68^{\circ} \mathrm{C}$ for $60 \mathrm{~min}$. DNA fragments bound to these probes were captured with Streptavidin MagneSphere ${ }^{\circledR}$ Paramagnetic Particles (Promega, USA) and eluated with DNase-free water after being washed four times in 0.1X SSC at room temperature. The microsatellite-enriched eluate was amplified and purified as described. The amplified products were purified with an Ultrafree column (Pall), and cloned using the pGEMT-easy system (Promega). Transformed colonies were screened for inserts by clone color and PCR test using M13 forward primer, nonbiotinylated microsatellite probes (noted earlier), and linker B as the primers. Positive clones were selected and sent to Sangon Biological Engineering Technology \& Services Co., Ltd. (Shanghai, China) for sequencing.

\section{Primer design and genotyping}

After removing the sequences of linkers and T vector, DNA sequences were searched against each other and against 9 spotted babylon microsatellite sequences from GenBank (accessed June 19, 2011) using Vector NTI Advance 11.0.0 (http://www.invitrogen.com) to check for duplicates. The MISA software (http://pgrc.ipk-gatersleben.de/misa/) was used to screen for sequences containing at least 6 di-, 5 tri-, 5 tetra-, 4 penta-, and 3 hexa-, hepta-, and octa-nucleotide repeats. Good sequences with sufficient flanking regions were selected for primer design with Primer3 (http://biotools.umassmed.edu/bioapps/primer3_www.cgi). An M13 (-21) universal leading sequence (5'-TGTAAAACGACGGCCAGT-3') was added to the $5^{\prime}$ end of each forward primer listed in Table 1 (Schuelke, 2000) and primers were synthesized by Sangon Biological Engineering Technology \& Services Co., Ltd.

All primer pairs were tested for PCR amplification in the 32 individuals of the Dd10 population. PCR was conducted in a $10-\mu \mathrm{L}$ solution containing about 50 ng template DNA, and reagents (TianGen) as follows: $1 \mathrm{X}$ reaction buffer containing $20 \mathrm{mM}$ Tris-HCl, $\mathrm{pH} \mathrm{8.4,} 20 \mathrm{mM}$ $\mathrm{KCl}$ and $10 \mathrm{mM}\left(\mathrm{NH}_{4}\right)_{2} \mathrm{SO}_{4}, 1.2 \mathrm{mM} \mathrm{MgCl}, 0.2 \mathrm{mM}$ of each dNTP, $0.4 \mathrm{U}$ Taq polymerase, 0.2 pmol M13 (-21) tailed forward primer, 0.8 pmol reverse primer, and 0.8 pmol M13 (-21) primer labeled with fluorescent dyes (FAM, VIC, NED, or PET; Applied Biosystems, Foster City, CA, USA). PCR was conducted on a Master Cycler Gradient (Eppendorf, Germany) with the following steps: $94^{\circ} \mathrm{C}$ for 4 min followed by 34 cycles of $94^{\circ} \mathrm{C}$ for $30 \mathrm{~s}$, annealing (temperatures indicated in Table 1) for $45 \mathrm{~s}, 72^{\circ} \mathrm{C}$ for $45 \mathrm{~s}$, followed by 10 cycles of $94^{\circ} \mathrm{C}$ for $30 \mathrm{~s}, 53^{\circ} \mathrm{C}$ for 45 $\mathrm{s}$, and $72^{\circ} \mathrm{C}$ for $45 \mathrm{~s}$, and a final extension at $72^{\circ} \mathrm{C}$ for $10 \mathrm{~min}$. Amplified products were detected and sized on an ABI 3130xl Prism Genetic Analyzer (Applied Biosystems) using GS-500LIZ (Applied Biosystems) as the size standard. Allele scoring was performed with GeneMapper v3.5 (Applied Biosystems). Samples failing to amplify the first time were reamplified once.

\section{Statistical analysis}

The MICRO-CHECKER 2.2.1 software (van Oosterhout et al., 2004) was used for identifying possible null alleles (1000 randomizations). GENEPOP on the web (http://genepop. curtin.edu.au/) was used to identify deviations from Hardy-Weinberg equilibrium (HWE) for each locus as well as for linkage disequilibrium (LD) between all pairs of loci (exact tests, 1000 iterations). The ARLEQUIN 3.0 software (Excoffier et al., 2005) was used to calculate observed $\left(H_{\mathrm{O}}\right)$ and expected $\left(H_{\mathrm{E}}\right)$ heterozygosities. All tests were corrected for multiple comparisons by Bonferroni's correction (Rice, 1989). 


\section{RESULTS}

\section{Microsatellite sequences}

One hundred and twenty-eight positive clones were sequenced, producing a total of 59,252 bp of DNA sequences. Analysis with MISA identified 118 microsatellite-containing sequences, corresponding to an enrichment efficiency of $97.5 \%$. The 118 microsatellite-containing sequences harbored 406 microsatellites with di- $(85.5 \%)$, tri- $(4.2 \%)$, tetra- $(6.2 \%)$, penta- $(0.7 \%)$, hexa- $(1.7 \%)$, and heptarepeats $(1.7 \%)$. Ninety $(76.3 \%)$ sequences contained more than one microsatellite. Most of these sequence contained clustered and complex repeated structures, while only 56 sequences had sufficient flanking regions for primer designing.

\section{Polymorphism and heterozygosity}

Eight primer pairs were successfully amplified and genotyped in 32 individuals from the Dd10 population (Table 1). The 8 microsatellite loci were polymorphic with allele numbers ranging from 6 at $H U B A 13$ to 18 at $H U B A 08$ (mean: $13.6 \pm 3.4$ ). The $H_{\mathrm{E}}$ and $H_{\mathrm{O}}$ varied from 0.68 at $H U B A 13$ to 0.94 at $H U B A 08$ (mean: $0.85 \pm 0.09$ ), 0.56 at HUBA13 to 0.81 at $H U B A 17$ and 22 (mean: $0.70 \pm 0.09$ ), respectively (Table 1). No linkage disequilibrium was detected among all the loci at $\mathrm{P}>0.05$ (after Bonferroni's correction). One locus (HUBA09) showed significant $(\mathrm{P}<0.05$ after Bonferroni's correction) deviation from HWE. HUBA09 and two other loci (HUBA08 and 15) showed signs of null alleles as indicated by MicroChecker (1000 randomizations) (Table 1), suggesting that the presence of null alleles was the main cause for the deviation from HWE. Samples that failed to amplify were rare (cf., Table 1), indicating that null homozygotes were not common.

Table 1. Primer sequences and characteristics of 8 Babylonia areolata microsatellite markers.

\begin{tabular}{|c|c|c|c|c|c|c|c|c|c|c|}
\hline Locus & GenBank acc. No. & Repeat motif ${ }^{\S}$ & Primer sequences $\left(5^{\prime}-3^{\prime}\right)$ & $\mathrm{Ta}\left({ }^{\circ} \mathrm{C}\right)$ & $\mathrm{N}$ & $N_{\mathrm{A}}$ & AS & $H_{\mathrm{E}}$ & $H_{\mathrm{O}}$ & $\mathrm{P}_{\mathrm{HWE}}$ \\
\hline$H U B A 08^{\dagger}$ & FJ595005 & $(\mathrm{GA})_{\mathrm{n}}(\mathrm{GACA})_{\mathrm{N}}$ & $\begin{array}{l}\text { F:agcagcctaacatacgcacac } \\
\text { R:attgaattgcagttggggaac }\end{array}$ & 62 & 29 & 18 & $166-236$ & 0.94 & 0.66 & 0.101 \\
\hline$H U B A 09^{\dagger}$ & FJ595006 & $(\mathrm{TG})_{\mathrm{N}}(\mathrm{AG})_{\mathrm{N}}$ & $\begin{array}{l}\text { F:agagttgagggactggtggag } \\
\text { R:tgtctaaaaccettatgcaggtg }\end{array}$ & 63 & 29 & 14 & $152-198$ & 0.90 & 0.63 & 0.000 \\
\hline$H U B A 13$ & FJ595010 & $(\mathrm{TTG})_{\mathrm{N}}$ & $\begin{array}{l}\text { F:gttttaccacgcgtactttgc } \\
\text { R:taaatcaaccttcccetaccc }\end{array}$ & 62 & 32 & 6 & 274-299 & 0.68 & 0.56 & 0.225 \\
\hline$H U B A 15^{\dagger}$ & FJ595012 & $(\mathrm{TG})_{\mathrm{N}}$ & $\begin{array}{l}\text { F:tcacccgtttctaaccettg } \\
\text { R:tttaagcaaccgagccaaac }\end{array}$ & 62 & 29 & 12 & $309-359$ & 0.90 & 0.63 & 0.183 \\
\hline HUBA17 & FJ595014 & $(\mathrm{AC})_{\mathrm{N}}$ & $\begin{array}{l}\text { F:cgcacgttcgatttgtaagac } \\
\text { R:gtttttccccagaggttgttc }\end{array}$ & 62 & 32 & 16 & $295-341$ & 0.91 & 0.81 & 0.134 \\
\hline HUBA20 & FJ595017 & $(\mathrm{TTG})_{\mathrm{N}}(\mathrm{TG})_{\mathrm{N}}(\mathrm{TC})_{\mathrm{N}}$ & $\begin{array}{l}\text { F:ctgggagttggttctgctatc } \\
\text { R:ttcaaatgccaaaggtagagg }\end{array}$ & 62 & 30 & 14 & $324-397$ & 0.81 & 0.78 & 0.029 \\
\hline$H U B A 21$ & FJ595018 & $(\mathrm{GA})_{\mathrm{n}}$ & $\begin{array}{l}\text { F:gtcatcgctggaatgaaaaag } \\
\text { R:ttctccatcaacccagcttc }\end{array}$ & 62 & 30 & 11 & $372-410$ & 0.80 & 0.72 & 0.273 \\
\hline HUBA22 & FJ595019 & $(\mathrm{CA})_{\mathrm{N}}$ & $\begin{array}{l}\text { F:ggcaacaaaactttcacttcg } \\
\text { R:cttcattgctgtcctttccac }\end{array}$ & 62 & 32 & 14 & $205-241$ & 0.89 & 0.81 & 0.058 \\
\hline
\end{tabular}

${ }^{\$}$ Repeat motif: $\mathrm{N}=$ pure; $\mathrm{n}=$ interrupted. Value in bold represents significant probability estimates after correction for multiple tests (initial $\alpha<0.05 / 8=0.00625$ ). "Loci showing evidence of null alleles suggested by Micro-Checker. $\mathrm{N}=$ number of individuals analyzed; $N_{\mathrm{A}}=$ number of alleles; $\mathrm{AS}=$ allele size range in base pairs; $H_{\mathrm{O}}$ and $H_{\mathrm{E}}=$ observed and expected heterozygosities; $\mathrm{Ta}=$ annealing temperature; $\mathrm{P}_{\mathrm{HWE}}=$ probability of Hardy-Weinberg equilibrium. 


\section{DISCUSSION}

There is probably a high frequency of microsatellite sequences in $B$. areolata genomes, since we obtained an enrichment efficiency of $97.5 \%$ (118 of 121) in this study, which is much higher than that obtained in four other molluscan species, whose microsatellite markers were developed in parallel in our laboratory using the same protocol and reagents: 63.3\% for Spisula solidissima (Wang et al., 2009b), 53.2\% for Pinctada maxima (Wang et al., 2009a), 59.4\% for Mercenaria mercenaria (Wang et al., 2010a), and 58.5\% for Haliotis diversicolor (Wang et al., 2011). In addition, we found clustered and complex repeated structures in the babylon genome. Extraordinarily, there were 76 microsatellite sequences $(64.4 \%$, 76 of 118) containing very long and complex microsatellites to have sufficient flanking regions for primer designing, and such high frequency was also observed by other researchers in B. areolata (Chen et al., 2009) and in other whelk, e.g., Buccinum undatum (Weetman et al., 2005). These results suggested that the $B$. areolata genome may be a good model to study the evolution of repetitive DNA sequences.

One locus (HUBA09) deviating from HWE and two other loci (HUBA08 and 15) may be influenced by one or more null alleles in the hatchery sample. This observation indicates that using HUBA09 for population genetic analyses that assume HWE may prove to be problematic, e.g., false homozygotes resulting from underestimation of heterozygotes (Pemberton et al., 1995), overestimation of $F_{\mathrm{ST}}$ and some reduction in the percentage of correctly assigned individuals in parentage assignment (Carlsson, 2008). Therefore, caution must to be taken when these markers are used.

The 8 polymorphic microsatellite markers developed here are a useful addition to the collection of other molecular markers that are now available for $B$. areolata, including the cytochrome oxidase subunit (CO) gene and the internal transcribed spacer 1 (ITS1) (Hualkasin et al., 2008), other microsatellite markers (Chen et al., 2009), and AFLP (Chen et al., 2011). They will prove valuable for future population genetic studies and in the tracking of hatchery strains in this species.

\section{ACKNOWLEDGMENTS}

Research supported by the National Basic Research Program of China (973 Program, \#2009CB126005), the National Natural Science Foundation of China (\#40866003 and \#31060354), and the Natural Science Foundation of Hainan (\#80616).

\section{REFERENCES}

Altena COVR and Gittenberger E (1981). The genus Babylonia (Prosobranchia, Buccinidae). Zool. Verh. 188: 1-57. Carlsson J (2008). Effects of microsatellite null alleles on assignment testing. J. Hered. 99: 616-623.

Chaitanawisuti N, Kritsanapuntu S and Natsukari Y (2002). Economic analysis of a pilot commercial production for spotted babylon, Babylonia areolata (Link, 1807), of marketable sizes using a flow-through culture system in Thailand. Aquacult. Res. 33: 1265-1272.

Chen CY and Chou HN (1998). Transmission of the paralytic shellfish poisoning toxins, from dinoflagellate to gastropod. Toxicon 36: 515-522.

Chen F, Ke CH, Wang DX, Chen J, et al. (2009). Isolation and characterization of microsatellite loci in Babylonia areolata and cross-species amplification in Babylonia formosae habei. Mol. Ecol. Resour. 9: 661-663.

Chen F, Luo X, Wang D and Ke C (2011). Population structure of the spotted babylon, Babylonia areolata in three wild 
populations along the Chinese coastline revealed using AFLP fingerprinting. Biochem. Syst. Ecol. 38: 1103-1110.

Excoffier L, Laval G and Schneider S (2005). Arlequin (version 3.0): an integrated software package for population genetics data analysis. Evol. Bioinform. Online 1: 47-50.

Hualkasin W, Tongchuai W, Chotigeat W and Phongdara A (2008). Phylogeography of Ivory shell (Babylonia areolata) in the Gulf of Thailand revealed by COI gene structure and differentiation of shell color by ITS1 DNA. Songklanakarin J. Sci. Technol. 30: 141-146.

Kritsanapuntu S, Chaitanawisuti N, Santhaweesuk W and Natsukari Y (2006). Growth, production and economic evaluation of earthen ponds for monoculture and polyculture of juveniles spotted babylon (Babylonia areolata) to marketable sizes using large-scale operation. J. Shellfish Res. 25: 913-918.

Liang F, Mao Y, Yu X and Liu H (2005). Experiment on artificial breeding of Babylonia areolata. Trans. Oceanol. Limnol. 1: 79-85.

Panichasuk P (1996). Areola Babylon, Babylonia areolata, Link 1807. Thai. Fish Gaz. 49: 107-117.

Pemberton JM, Slate J, Bancroft DR and Barrett JA (1995). Nonamplifying alleles at microsatellite loci: a caution for parentage and population studies. Mol. Ecol. 4: 249-252.

Reece KS, Ribeiro WL, Gaffney PM, Carnegie RB, et al. (2004). Microsatellite marker development and analysis in the eastern oyster (Crassostrea virginica): Confirmation of null alleles and non-Mendelian segregation ratios. J. Hered. 95: 346-352.

Rice WR (1989). Analyzing tables of statistical tests. Evolution 43: 223-225.

Schuelke M (2000). An economic method for the fluorescent labeling of PCR fragments. Nat. Biotechnol. 18: 233-234.

Supanopas P, Sretarugsa P, Kruatrachue M, Pokethitiyook P, et al. (2005). Acute and subchronic toxicity of lead to the spotted babylon, Babylonia areolata (Neogastropoda, Buccinidae). J. Shellfish Res. 24: 91-98.

van Oosterhout C, William FH, Derek PMW and Peter S (2004). Micro-checker: software for identifying and correcting genotyping errors in microsatellite data. Mol. Ecol. Notes 4: 535-538.

Wang Y, Liu N, Shi Y, Gu Z, et al. (2009a). Development and characterization of sixteen new microsatellite markers for the white-lipped pearl oyster, Pinctada maxima (Jameson, 1901). Mol. Ecol. Res. 9: 1460-1466.

Wang Y, Wang A and Guo X (2009b). Development and characterization of 30 polymorphic microsatellite markers for the Atlantic surfclam, Spisula solidissima (Dillwyn, 1817). Mol. Ecol. Resour. 9: 1264-1267.

Wang Y, Wang A and Guo X (2010a). Development and characterization of polymorphic microsatellite markers for the northern quahog Mercenaria mercenaria (Linnaeus, 1758). J. Shellfish Res. 29: 77-82.

Wang Y, Wang X, Wang A and Guo X (2010b). A 16-microsatellite multiplex assay for parentage assignment in the eastern oyster (Crassostrea virginica Gmelin). Aquaculture 308: S28-S33.

Wang Y, Wang F, Shi YH, Gu ZF, et al. (2011). Development and characterization of 60 microsatellite markers in the abalone Haliotis diversicolor. Genet. Mol. Res. 10: 860-866.

Weetman D, Hauser L, Shaw PW and Bayes M (2005). Microsatellite markers for the whelk Buccinum undatum. Mol. Ecol. Notes 5: 361-362. 